\title{
FINANCIERING VAN BANKEN DOOR MIDDEL VAN DEPOSITO-OBLIGATIES
}

\author{
door Prof. Dr. C. F. Scheffer
}

\section{Inleiding.}

Gaarne wordt dezerzijds voldaan aan het verzoek van de Redactie om - naar aanleiding van de onlangs door de Amsterdamsche Bank uitgegeven deposito-obligaties - een beschouwing te geven over bovenvermeld onderwerp.

Het lijkt een goede gedachte om eens enkele facetten van het financieringsvraagstuk bij de banken te belichten en aldus deze irstellingen in een bedrijfseconomische analyse te betrekken. Het bankwezen, met name voor zover dit een geldscheppend karakter draagt, heeft een zodanige maat schappelijke betekenis dat - zeker in ons land - zijn problemen in overwegende mate geacht worden te behoren tot het terrein van de sociale economie en de behandeling der bedrijfseconomische aspecten veelal tussen de wal en het schip terecht komen. Limperg heeft er destijds in zijn bekende opstellen over "Het object der bedrijfshuishoudkunde" in dit Maandblad op gewezen, ,dat de natuurlijke scheidingslijn tussen sociale economie en bedrijfseconomie hier een afbuiging vertoont" en ,dat de schematische voorstelling van de verbijzondering in de economie op dit punt aesthetische bedenkingen doet rijzen." Niettemin was hij van mening. ,.dat de weg, die in Nederland te dezen aanzien is gevolgd, doelmatig gekozen is, omdat hij is aangepast aan de behoefte aan arbeidsverdeling en verbijzondering der werkelijkheid" 1).

Hoezeer erkend moet worden, dat de behandeling van het bankwezen een belangrijke plaats dient te hebben in de algemene economie, en er alle aanleiding bestaat om de gebruikelijke specialisatie op dit punt te handhaven, kan het toch nuttig geacht worden aan de bedrijfseconomische aspecten van het bankbedrijf - met name in de Leer van de Financiering aandacht te besteden. Daarbij zal echter ten volle rekening gehouden dienen te worden met de algemeen-economische of liever gezegd de monetaire aspecten, omdat deze bepalend zijn, met name voor het karakter van het overgrote deel der aan de algemene banken toevertrouwde middelen en haar geldscheppend vermogen. Aan dit laatste moge daarom thans eerst enige aandacht worden geschonken. Herhaaldelijk blijkt hieromtrent misverstand te bestaan. Nog onlangs bleek dit uit een artikel van W. N. de Blaey in de E.S.B. van 2 november 1955, hetwelk eveneens de deposito-obligatie behandelde. Mede naar aanleiding daarvan menen wij eerst over de geldschepping te moeten spreken. Daarbij komen wij op bedoeld artikel nader terug.

\section{Geldschepping.}

In onze inaugurale rede ${ }^{2}$ ) te Tilburg hebben wij er op gewezen, dat de beschouwingswijze welke men in bedrijfseconomische leerboeken tegenkomt, n.l. dat via de primaire banken welke geen circulatiebank zijn beschikkingsmacht wordt overgedragen, slechts ten dele juist is en in strijd is

1) Th. Limperg Jr.: Het object der bedrijfshuishoudkunde, Purmerend 1952, blz. 24.

2) C. F. Scheffer: Indeling en ontleding van de vraagstukken, behorende tot het financiewezen van de Onderneming op basis van de traditionele geldfuncties, Groningen 1955 , blz. $15 / 16$. 
met wat de monetaire economie ten deze leert. De direct opvraagbare tegoeden bij deze banken, waarover per chèque of giro kan worden beschikt hebben het karakter van geld en zijn, economisch gezien, niet te onderscheiden van het chartale geld. Wanneer deze tegoeden ontstaan door storting van chartaal geld, wordt het laatste vernietigd in economische zin. Het maakt in de kas van de betr. bank geen deel meer uit van de maatschappelijke geldhoeveelheid. De beschikkingsmacht blijft volledig bij de houder van het girale tegoed. Van overdracht is geen sprake. Volkomen juist zegt de Amsterdamsche Bank in het emissie-prospectus der deposito-obligaties over deze saldi, dat zij ,, bij voortduring als liquiditeit ter beschikking van het bedrijfsleven en publiek blijven."

Wanneer het chartale geld uit de kassen van de primaire banken - b.v. door credietverlening - weer in het verkeer komt heeft per definitie geldschepping plaats. Nu zou men kunnen opmerken, dat deze beschouwingswijze in wezen toch niet afwijkt van de theorie, welke van ,overdracht" van beschikkingsmacht spreekt. De quintessence ligt echter in het feit, dat over geopende credieten voor een deel op girale wijze wordt beschikt, waardoor wel degelijk méér beschikkingsmacht in totaal kan worden uitgeoefend dan oorspronkelijk aan chartaal geld bij de banken werd gestort. Behalve door omzetting van chartaal in giraal geld - en abstraherend van allerlei transformaties - blijkt het girale geld nog op de volgende wijze te ontstaan:

$A$. Uit verleende credieten, waarover wordt gedisponeerd door overboeking bij dezelfde bank;

$B$. Uit verleende credieten, waarover wordt gedisponeerd door overboeking op rekeningen bij andere banken.

In geval $A$. zullen de liquide middelen van de betreffende bank niet worden aangetast. $Z_{i j}$ zal hoogstens eventueel moeten zorgen voor een groter bedrag aan disponibiliteiten, afhankelijk van het op de ervaring berustende of wettelijk voorgeschreven percentage, omdat de liquiditeitsverhouding uiteraard wel is verslechterd.

In geval $B$. verliest de credietgevende bank liquide middelen voor het volle bedrag van de overboeking, hetwelk via de clearing moet worden afgedekt. Aangezien echter tussen de banken over en weer regelmatig deze transacties plaats vinden, is duidelijk dat door wederzijdse overboekingen het girale geld kan aangroeien, zonder dat nochtans de liquiditeit der individuele banken wijziging ondergaat, mits de omvang der overboekingen over en weer gelijk is en het tempo daarvan gelijkmatig verloopt. Vanzelfsprekend zullen de individuele banken wel haar disponibiliteiten moeten verhogen naarmate de opvraagbare saldi toenemen.

In een financieel-ontwikkeld land als het onze mag worden aangenomen dat over het geheel der verleende credieten in belangrijke mate op girale wijze wordt beschikt. Hoewel onderzoekingen in dit opzicht ten onzent voor zover dezerzijds bekend - niet werden verricht mag op grond van boven gegeven analyse worden aangenomen, dat wanneer de banken in gelijk tempo en in gelijke omvang haar credietverlening uitbreiden tot een zeker deel daarvan ook de creditsaldi bij de banken zullen toenemen. Dit deel behoeft niet in overeenstemming te zijn met het percentage, hetwelk de totale hoeveelheid giraal geld uitmaakt van de totale geldhoeveelheid (in ons land $\pm 60 \%)$, omdat er ook nog andere oorzaken van geldcreatie zijn, waarop we hier niet kunnen ingaan. Het is echter duidelijk dat de toevloeiing van creditgelden ten dele het gevolg is van de credietverlening en daardoor a.h.w. wordt geinduceerd. De banken kunnen dit geldschep- 
pingsproces op gang houden, mits zij in de pas blijven lopen 3 ) en in staat zijn de disponibiliteiten procentueel aan te passen aan de toename der opvraagbare middelen. Dit laatste is afhankelijk van eventuele overliquiditeit, en in chartale vorm netto-toevloeiende middelen uit welken hoofde ook. Dit is de basis waarop de credietgeving kan worden opgetrokken en welke het uitgangspunt zou kunnen vormen voor de berekening der maximale credietuitzetting voor het geheel der algemene banken - niet echter voor de individuele bank.

Wij kunnen ons dan ook niet verenigen met de door W. N. de Blaey in de E.S.B. van 2 november j.1. ontwikkelde gedachte dat gegeven het bedrag aan termijn-deposito's en een voorgeschreven percentage aan liquide middelen de maximale credietuitzetting voor een bank te berekenen is. Toegepast op de cijfers van de Amsterdamsche Bank per 31 december 1954 stelt de Blaey bij een liquiditeit van $40 \%$ : Termijndeposito's $f 172.809$, Maximale credietschepping $21 / 2 \times f 172.809,-\ldots 432.022,-$ Maximale credietverlening f 604.831 , -

De Blaey concludeert op grond hiervan: ,Vergelijken wij dit met de werkelijke credietschepping ad $f$ 428.783, - (debiteuren minus termijndeposito's) dan blijkt dat de grenzen èn van credietschepping en credietverlening bij de Amsterdamsche Bank practisch beteikt zijn" 4).

Zonder in te gaan op de o.i. onjuiste term credietschepping, op het feit dat alleen de termijndeposito's als basis worden genomen en op het feit dat de totale liquiditeiten en niet de disponibiliteiten als maatstaf worden genoemd, terwijl geabstraheerd wordt van de vraag of ook tegenover de termijndeposito's geen liquiditeiten moeten worden aangehouden, kan worden gesteld, dat de Blaeys' berekening niet acceptabel is, omdat zijn veronderstellingen alleen zouden opgaan als de bank - voor wat de credietverlening betreft - in de pas blijft met de overige banken.

Wij geloven dat het van belang is dit facet in het oog te houden ook bij de bestudering van het financieringsvraagstuk bij de banken.

\section{Algemeen financieringsaspect.}

In de geldschepping wordt door de individuele bankier - Prof. Kaag heeft het in zijn laatste Diës-rede weer eens duidelijk gezegd - slechts ternauwernood geloofd. Dit is overigens alleszins begrijpelijk. Maatschappelijk is ook slechts de totale netto-geldcreatie relevant en dat is een zaak van het bankwezen in zijn geheel. De individuele bank ziet slechts opvraagbare creditsaldi en vraagt zich niet af of deze door de credietverlening zijn geïnduceerd dan wel een autonoom karakter dragen.

De individuele bank ziet op de eerste plaats het liquiditeitsvraagstuk. $Z_{\text {ij }}$ streeft ongetwijfeld naar een rendabele aanwending van de naar haar toegevloeide middelen doch deze dient vóó alles in overeenstemming te zijn met het karakter daarvan. $Z_{\mathrm{ij}}$ put de middelen voor de credietverlening ten dele uit het eigen kapitaal en de reserves, ten dele uit deposito's en rekeningcourantsaldi. $Z_{\text {ij }}$ zal in laatstgenoemde - hoewel dagelijks opzegbaar - een permanente kern constateren. In het bijzonder bij de banken met wijd vertakt filialennet over het gehele land en met een kring van relaties, verdeeld over velerlei bedrijfstakken, zal een grote regelmaat te con-

3) „In de pas lopen" is een uitdrukking, welke voor bedoeld verschijnsel algemeen wordt gebezigd.

4) W. N. de Blaey: Deposito-obligaties, in E.S.B. van 2 november 1955, blz. 984. 
stateren zijn in het totale bedrag der toevertrouwde middelen. Tegenover de bedragen, welke van dag tot dag worden teruggevraagd staan andere welke dagelijks naar haar toevloeien. Het bekende diversiteitsverschijnsel is ook hier werkzaam.

Mede op grond hiervan acht zij het verantwoord ook ten dele met opvraagbare saldi credieten in rekening-courant te verstrekken, die weliswaar formeel dagelijks opvraagbaar zijn, doch in feite lang niet altijd op korte termijn realiseerbaar. De korte credietverlening vormt ten onzent volgens deskundigen - o.a. Prof. Dr. G. M. Verrijn Stuart ${ }^{5}$ ) - nog altijd de hoofdschotel der uitzettingen, zij het dat volgens deze schrijver „,ook hier te lande de credietverlening à moyen terme is toegenomen" 6 ). Exacte gegevens staan daaromtrent niet ter beschikking.

Saldi in rekening-courant vormen bij de Nederlandse banken het voornaamste deel der toevertrouwde middelen. De termijndeposito's spelen slechts een geringe rol. Per ultimo oktober 1955 beliep het totaal der in rekeningcourant toevertrouwde gelden aan de 35 representatieve handels banken ruim $f 4$ milliard, terwijl de totale deposito's voor één maand of langer $f 1,4$ milliard beliepen.

De obligatie-lening kwam tot dusver bij de algemene banken in Nederland niet voor en daaraan bestond, in verband met de uitzettingen ook geen behoefte. Voor de algemene bank, welke in hoofdzaak kort crediet verleent lijkt de obligatie een weinig adequaat financierings-instrument, zowel uit het oogpunt van kosten als uit het oogpunt van liquiditeit. De te betalen rente is hoog in verhouding tot de bij de algemene banken traditionele financierings-instrumenten, alsook in verhouding tot hetgeen aan credietnemers in rekening wordt gebracht. De lange termijn waarvoor de lening wordt aangetrokken is niet aangepast aan de wisselende credietbehoeften, tenzij men de emissie conjunctureel juist zou weten te timen. Bij leegloop - en dat is in feite aanvankelijk steeds het geval - wanneer de aangetrokken middelen tijdelijk op de geldmarkt moeten worden uitgezet, waar de rentestand lager ligt, leidt de financiering met obligaties tot renteverliezen. Voorts is er het nadeel dat een aanmerkelijke liquiditeitsspanning verwekt wordt tegen de tijd dat de lening moet worden afgelost, terwijl geenszins vaststaat of de kapitaalmarkt op dat moment tot opname van een nieuwe obligatielening in staat en bereid is.

Geleidelijke aflossing is alleen zinvol indien dit niet betekent een schoksgewijze inkrimping van beschikbare middelen zonder meer, doch afgestemd zou zijn op overeenkomstige wijzen van credietverlening, zoals het geval is bij de hypotheekbank. Bij deze instelling kan de obligatie een adequaat financierings-instrument worden genoemd. De aflossingen worden hier aangepast aan de afgeloste hypotheken. Bovendien vindt de plaatsing van de pandbrieven als regel „over de toonbank" plaats, hetgeen eveneens de aanpassing aan de actieve financiering van de bank vergemakkelijkt ${ }^{7}$ ).

Tenslotte moge als nadeel van de bankobligatie - uitgezonderd die met korte looptijd - in het algemeen nog worden genoemd de mogelijke koersdaling ter beurze, welke het vertrouwen schokt en de banken noopt tot steunverlening. Belening der eigen obligaties zal bij geschokt vertrouwen bezwaarlijk kunnen worden geweigerd en daardoor wordt de functie

5) Zie diens artikel: Tien jaar bankpolitiek, in de onlangs verschenen jubileumbundel van de Herstelbank.

6) t.a.p. blz. 66 .

7) Vgl. O. Bakker: Bedrijfshuishoudkunde Deel II blz. 204.

ma b blz. 116 
van de obligatie als instrument tot aantrekking van middelen, welke langdurig ter beschikking staan min of meer illusoir.

\section{Zwitserland.}

Het klassieke voorbeeld voor de toepassing van de bankobligatie, waarnaar ook tenonzent bij de emissie der deposito-obligaties door de Amsterdamsche Bank werd verwezen, is Zwitserland ${ }^{8}$ ). Ook België heeft men genoemd. Men dient hierbij echter wel te bedenken, dat het karakter der $Z$ witserse obligaties anders is dan boven bedoeld en dat de structuur van de uitzettingen der Zwitserse banken anders is dan ten onzent. De Zwitserse „Kassenobligationen" hebben als regel een looptijd van 3 tot 8 jaar. Zij worden verkocht aan de loketten van de banken, zodat feitelijk niet van .,emissies" sprake is. $Z_{\mathrm{ij}}$ worden niet aan de $\mathrm{Z}$ witserse beurzen genoteerd, doch zijn wel beleenbaar. Gezien het aanzienlijke bedrag, dat uitstaat mag worden aangenomen dat deze obligaties een gewild beleggingsobject zijn in Zwitserland. Per ultimo 1954 bedroeg het totale uitstaande bedrag aan kasobligaties fr. 5.663 mill, waarvan bijna de helft $(45,1 \%)$ ten laste van de Kantonalbanken en $17,8 \%$ ten laste van de grootbanken 9 ).

$\mathrm{Bij}$ de Kantonalbanken betekent dit $20 \%$ van het balanstotaal, bij de grootbanken $10,43 \% 10)$. De Kantonalbanken hebben een typisch gemengd karakter. $Z_{i j}$ houden zich zowel bezig met het hypothecaire crediet als met het handelscrediet. Het eerst genoemde beliep ultimo $195458,7 \%$ van het balanstotaal tegen het handelscrediet 10.6\% 11). De grootbanken bewegen zich ook op beide terreinen, doch daar liggen de verhoudingen enigszins anders en gelden resp. de volgende percentages $8,3 \%$ en $27,4 \%$.

Bovendien kennen beide groepen van banken de z.g. vaste voorschotten „avances et prêts a terme fixe" welke bij de Kantonalbanken 7,4\% en bij de grootbanken $9,17 \%$ van het balanstotaal uitmaken. Waar het op aankomt is, dat de kasobligaties voor een groot deel te vinden zijn bij de Kantonalbanken, welke zich in belangrijke mate bezig houden met het hypothecaire crediet, waarvoor zij de middelen verder vinden in spaartegoeden (38,5\% van het balanstotaal). Bij de grootbanken vormen de girorekeningen $44,2 \%$ van het balanstotaal en daarmee de voornaamste middelenbron. Voor de representatieve handelsbanken in Nederland ligt dit percentage op ca. $55 \%$. Wij geloven, dat de verwijzing naar Zwitserland docr het totaal afwijkende karakter juist van de Kantonalbanken weinig zegt. Overigens dragen de kasobligaties hier het karakter van een speciale vorm van deposito-crediet. Hierop heeft reeds Landmann in het Handwörterbuch der Staatswissenschaften in 1924 gewezen. Het is niet anders dan een door de banken aangenomen gewoonte om deposito's met vaste tijdsduur in ronde sommen op te nemen en de daaruit ontstane rechtsverhouding in een obligatie vast te leggen ${ }^{12}$ ).

"Geht man ihrem Ursprung nach, so sieht man, wie zuerst die Kassascheinen für Depositen in runden Summen, die man auf gewisse Termine (3.6 Monate) der Bank einzahlte, abgegeben wurden. Nachher schob man

8) Zie Nederlardse Bankiersvereniging - Bulletin Nr. 289 dd 7-12-55 en het Financiële Dagblad dd. 13 october 1955.

9) Das Schweizerische Bankwesen in Jahre 1954, Mitteilungen der volkswirtschaftlichen und statistischen Abteilung der Schweizerischen Nationalbank 38. Heft. blz. 40.

10) idem, blz. 138 tabel 5 .

11) idem, blz. 167 tabel 30.

12) J. C. M. van Rhee: De betrekkingen tussen banken en industrie in Zwitserland, Rotterdam 1934, blz. 130.

$\mathrm{mab}$ blz. 117 
der Kündigung eine Frist vor, während der das Guthaben unkündbar war. Diese Frist wurde immer länger zuerst 3, dann 6, 9, 12 Monate, 2, 3 und mehr Jahre. So hat sich nach und nach der heutige Typus der Kassaobligation gebildet," zegt Wetter 13). De Zwitserse kasobligaties dragen eigenschappen zowel van het deposito als van de obligatie en deposito-obligaties zou voor deze mengvorm een geschikte naam zijn. Het uiterlijk is dat van de obligatie, terwijl zij ook de overdraagbaarheid en beleenbaarheid daarmede gemeen heeft. Het initiatief tot deze credietverstrekking ligt hier echter niet bij de geldnemer maar bij de geldschieter en dit laatste is een typische karaktertrek van het deposito. De kasobligatie is altijd verkrijgbaar; de toevoer tracht men slechts - evenals bij het deposito - door middel van de rente te regelen. Bij een obligatie-emissie zoals ten onzent die der Amsterdamsche Bank ligt het initiatief bij de geldnemer! O.i. ontbreekt daaraan het deposito-karakter.

T.a.v. de Belgische kasobligaties moge worden volstaan met het volgende: $\mathrm{Zij}$ worden uitgegeven voor de financiering van middellange exportcredieten door de banken: zij lopen gewoonlijk 3 jaar; zij zijn beleenbaar; het totale uitstaande bedrag per 31 augustus j.l. ad frs. 3.472 mill heeft op het balanstotaal der Belgische banken ad frs. 109.178 mill. weinig betekenis ${ }^{14}$ ).

Door de regelmatige uitgifte van de kasobligaties wordt voor de banken een regelmatig vloeiende financieringsbron aangeboord, welke inderdaad van betekenis kan worden geacht met het oog op de verstrekking van middellang crediet.

In Zwitserland beliep ultimo 1954 de gemiddelde looptijd van alle uitstaande kasobligaties 3 jaar en 7 maanden. $Z$ ij nemen de bezwaren verbonden aan de eenmalige uitgifte van obligaties ten dele weg.

\section{Enige richtlijnen.}

Wij zouden thans aan de hand van het voorafgaande enige richtlijnen willen aangeven voor de financiering van banken met obligaties in het algemeen en de toepassing daarvan in Nederland.

a. De uitgifte van obligaties door banken is in het algemeen slechts aan te bevelen ter verlening van lang lopende credieten, en wel zó, dat uitgifte en terugbetaling kunnen worden afgestemd op verlening en aflossing van de credieten. Leegloop is ongewenst en onvoordelig.

b. De eenmalige obligatielening voldoet niet aan deze eis. $Z_{\text {ij }}$ draagt ook niet het karakter van de $Z$ witserse kasobligaties, waarbij juist de continue uitgifte essentieel is.

c. Bankobligaties zijn bij de verhoudingen in het Nederlandse bankwezen slechts aan te bevelen wanneer zou blijken dat de aard der credietgeving, welke tot nog toe overwegend kort was, zou zijn gewijzigd.

d. Een eenmalige obligatielening kan wellicht worden gemotiveerd omdat bepaalde verhoudingen zijn scheefgegroeid, dan wel de betreffende bank in de credietverlening de pas met de overige instellingen is $k$ ijt geraakt. (zie onder 2 ).

\section{Amsterdamsche Bank.}

Zo komen we dan aan het geval van de Amsterdamsche Bank. Wij willen de volgende vragen onder het oog zien: Waarom gaf de Amsterdamsche

13) Geciteerd in voetnoot bij Rhee blz. 130.

14) Ontleend aan het in noot ${ }^{8}$ ) genoemde Bulletin.

m a b blz. 118 
Bank obligaties uit? Is dit de introductie van een novum, dat door de andere banken zal worden gevolgd of een incidenteel geval?

De balans van de Amsterdamsche Bank per 31 december 1954 vertoonde het volgende beeld. (in 1000 gld.)

\begin{tabular}{|c|c|c|c|}
\hline Kas, kassiers etc. & $f \quad 138.618$ & Kapitaal & 70.010 \\
\hline Opbouwobl. en bel. cert. & 57.322 & Reservefonds & 50.000 \\
\hline Ned. Schatkistpapier & " 446.762 & Onverd. Winstsaldo & 291 \\
\hline Ander Overheidspapier & " $\quad 34.708$ & Deposito's op termijn & . $\quad 172.809$ \\
\hline Wissels & 22.158 & Crediteuren & " 1.181 .963 \\
\hline Bankiers & 68.959 & Genomen daggeldl. & . $\quad 5.500$ \\
\hline Effecten en syndicaten & 37.405 & Geacc. Wissels & 9.641 \\
\hline Prol. en voorsch. op & & Door derden geaccept. & 241 \\
\hline effecten & 76.335 & Dividend & 7.000 \\
\hline Debiteuren & 600.592 & Uitk, uit agioreserve & 1.400 \\
\hline \multicolumn{4}{|l|}{ Deelnemingen } \\
\hline (incl. voorsch.) & 15.996 & & \\
\hline \multirow{2}{*}{ Gebouwen etc. } & P.M. & & \\
\hline & f 1.498 .855 & & $f 1.498 .855$ \\
\hline
\end{tabular}

Wanneer we nu aannemen dat de eigen middelen primo staan tegenover de deelnemingen en het restant daarna met de termijndeposito's en het bedrag der crediteuren, dat niet in liquide vorm wordt aangehouden voor credietverlening beschikbaar is dan kan de volgende opstelling worden gemaakt:

Liquiditeiten van

\begin{tabular}{|c|c|}
\hline $\begin{array}{l}\text { Eigen middelen } \\
\text { Vastleggingen }\end{array}$ & $\begin{array}{lr}f & 120.301 \\
\text {, } & 15.996\end{array}$ \\
\hline $\begin{array}{l}\text { Deposito's } \\
\text { Crediteuren }\end{array}$ & f 1.181 .963 \\
\hline
\end{tabular}

$1 \mathrm{e}, 2 \mathrm{e}$, en $3 \mathrm{e}$ orde

Nostro-gelden en verval-

f 882.267

len verplichtingen te beschouwen als negatieve liquiditeit
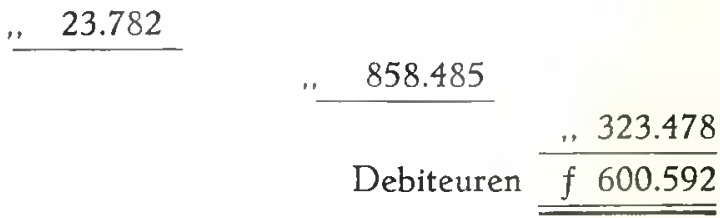

Hieruit kan worden berekend, dat per 31 december 1954 de Debiteuren als volgt werden gefinancierd:

voor $53,8 \%$ met direct opvraagbare middelen,

voor $28,9 \%$ met à deposito verkregen middelen,

voor $17,3 \%$ met eigen middelen 15 ).

15) De aandacht moge er op worden gevestigd, dat onder debiteuren uitsluitend de rekening-courant-debiteuren zijn opyenomen en niet de voorschotten op effecten en prolongaties. Deze laatste zijn als liquiditeit van hogere orde beschouwd. Het spreekt vanzelf dat 
Aan de hand van de maandstaat per 31 augustus 1955 kan worden berekend, dat deze cijfers per die datum resp. bedroegen: $55,4 \%, 29,7 \%$ en $14,9 \%$, zodat een onbelangrijke verschuiving heeft plaats gevonden.

Relevant is verder, dat per 31 december 1954 het totaal der opvraagbare saldi voor ruim $73 \%$ gedekt was door liquiditeiten van verschillende orde en voor ruim $11 \%$ door disponibiliteiten 16 ).

Per 31 augustus 1955 bedroegen deze cijfers resp. ca. $71 \%$ en ca. $10 \%$.

Vergelijken we deze gegevens met dezelfde verhoudingen bij de representatieve algemene banken gezamenlijk en bij enkele grootbanken afzonderlijk, waarvoor wij dezelfde berekeningen hebben gemaakt, dan zien wij het volgende:

\begin{tabular}{|c|c|c|c|c|c|c|c|c|c|c|}
\hline & \multicolumn{6}{|c|}{ Percentage Debiteuren gefinancierd met } & \multirow{2}{*}{\multicolumn{2}{|c|}{$\begin{array}{l}\text { Liquiditeiten } \\
\text { in } \% \text { dir. } \\
\text { opvr. } \\
\text { middelen }\end{array}$}} & \multirow{2}{*}{\multicolumn{2}{|c|}{$\begin{array}{l}\text { Disponi- } \\
\text { biliteiten } \\
\text { in } \% \text { dir. } \\
\text { opvr. } \\
\text { middelen }\end{array}$}} \\
\hline & \multicolumn{2}{|c|}{$\begin{array}{l}\text { Eigen } \\
\text { middelen }\end{array}$} & \multicolumn{2}{|c|}{ Deposito's } & \multicolumn{2}{|c|}{$\begin{array}{c}\text { direct } \\
\text { opvr. } \\
\text { middelen }\end{array}$} & & & & \\
\hline & $\begin{array}{l}\text { uit. } \\
1954\end{array}$ & $\begin{array}{l}\text { ut. } \\
\text { Aug. } \\
1955 \\
\end{array}$ & $\begin{array}{l}\text { ult. } \\
1954\end{array}$ & $\begin{array}{l}\text { u } \\
\text { Aug. } \\
1955\end{array}$ & $\begin{array}{l}\text { ulk. } \\
1954\end{array}$ & $\begin{array}{l}\text { ult. } \\
\text { Aug. } \\
1955 \\
\end{array}$ & $\begin{array}{c}\text { ult. } \\
1954\end{array}$ & $\begin{array}{l}\text { ult. } \\
\text { Aug. } \\
1955\end{array}$ & $\begin{array}{l}\text { ult. } \\
1954\end{array}$ & $\begin{array}{r}\text { ult. } \\
\text { A ug } \\
1955 \\
\end{array}$ \\
\hline \multirow{4}{*}{$\begin{array}{l}\text { Totaal represen- } \\
\text { tatieve banken } \\
\text { Amsterdamsche } \\
\text { Bank } \\
\text { De Twentsche } \\
\text { Bank } \\
\text { Rotterdamsche } \\
\text { Bank }{ }^{17} \text { ) }\end{array}$} & 24,9 & 22,1 & 61,7 & 53,5 & 13,4 & 24,4 & 94,7 & 89,2 & 13,7 & 12,1 \\
\hline & 17.3 & 14.9 & 28.9 & 29.7 & 53.8 & 55.4 & 73 & 71 & 11 & 10 \\
\hline & 18,4 & 25,5 & 81,6 & 57,8 & 0 & 16,7 & 104,4 & 89,1 & 13,8 & 10,2 \\
\hline & 30,9 & & 57,4 & & 11,7 & & 94,7 & & 13,7 & \\
\hline
\end{tabular}

Zonder een oordeel te willen uitspreken over de weergegeven verhoudingen als zodanig, kan worden geconstateerd, dat deze bij de Amsterdamsche Bank ongunstig afstaken bij die der representatieve banken als geheel en bij De Twentsche Bank en de Rotterdamsche Bank in het bijzonder.

Het mag derhalve waarschijnlijk geacht worden dat de uitgifte der deposito-obligaties mede ten doel had de verhoudingen enigszins recht te trekken. Een geringe verbetering komt reeds ultimo november 1955 tot uitdrukking. Per die datum bleken de credieten voor 36,1\% met deposito's te zijn gefinancierd en voor $49,7 \%$ met opvraagbare middelen. De totale liquiditeiten bedroegen toen $74,3 \%$ der direct opvraagbare gelden en de disponibiliteiten $12,9 \%$. Niettemin blijft de positie nog afwijkend van die der overige banken.

In dit verband behoeft het niet uitgesloten te worden geacht, dat opnieuw nog eens een dergelijke emissie van obligaties door de Amsterdamsche Bank aan de markt zou komen. Tevens kan worden opgemerkt, dat daaraan bij De Twentsche Bank en de Rotterdamsche Bank op deze grond geen behoefte bestaat.

Zoals reeds sub $5 \mathrm{~d}$ vermeld, kan naast scheef getrokken verhoudingen ook het uit de pas geraken als motief voor eenmalige uitgifte van obligaties gelden. Staan wij hier tot slot nog een ogenblik bij stil. Een bank raakt o.i.

dit invloed heeft op de verhoudingscijfers en wel in die zin, dat het percentage voor de direct opvraagbare middelen geflatteerd is en de percentages voor de eigen middelen en de deposito's iets te ongunstig uitkomen. Dit geldt voor alle in het volgende voorkomende berekeningen van deze aard.

16) Onder disponibiliteiten verstaan wij uitsluitend primaire liquiditeit, de z.g. „greifbare Mittel".

17) De Rotterdamsche Bank publiceert geen maandstaten meer.

m a b blz. 120 
de pas kwijt, wanneer zij haar credietverlening sterker en/of sneller uitbreidt dan de overige banken, dan wel het karakter harer credieten zich wijzigt, b.v. doordat men deze gaat verstrekken voor andere doeleinden dan gebuikelijk was en wel zodanig dat de debetsaldi gemiddeld langer uitstaan dan voorheen. Wanneer hier over credietverlening wordt gesproken, denken wij n.l. steeds aan netto-credietverlening over een bepaalde periode. Wijziging in de termijnen, gedurende welke credieten uitstaan, leidt in toekomstige perioden - ceteris paribus - tot grotere netto-credietverlening.

In het emissieprospectus wijst de Amsterdamsche Bank erop ,.dat in de tien jaren, die sedert het beëindigen van de wereldoorlog zijn verstreken de relatieve betekenis van de debiteurenportefeuille aanzienlijk is toegenomen". Het komt ons voor dat de credietverlening bij haar ook sterker is gestegen dan bij de overige banken. Dit is zeker het geval geweest in de periode 1950 - 1954, zoals uit de volgende cijfers moge blijken.

Debiteuren in percentage van het balanstotaal.

\begin{tabular}{l|c|c}
\hline & ult. 1950 & ult. 1954 \\
\hline Representatieve banken ${ }^{18}$ ) & & \\
Amsterdamsche Bank & 20,9 & 25,8 \\
De Twentsche Bank & 28,1 & 40,8 \\
Rotterdamsche Bank & 23,0 & 26,3 \\
& 19,2 & 25,4 \\
\hline
\end{tabular}

Stijgingspercentage debiteuren van ultimo 1950 tot ultimo 1954 .

Representatieve banken

Amsterdamsche Bank

50,7

De Twentsche Bank

90.5

Rotterdamsche Bank

59.6

73.1

De cijfers van de laatste tabel moeten met grote voorzichtigheid worden gehanteerd, omdat de balanscijfers der beide jaren niet helemaal vergelijkbaar zijn. Niettemin geloven wij eruit te mogen aflezen, dat de Amsterdamsche Bank bij de credietverlening in de afgelopen 5 jaren enigszins uit de pas is geraakt. Dit kan mede aanleiding zijn geweest om op bijzondere wijze haar middelen te versterken.

Is er ook wijziging gekomen in de aard der credietverlening? ,De aard der credietverlening is bij dit alles niet veranderd", zo werd in het prospectus opgemerkt. Het is echter niet helemaal duidelijk wat hier met de aard van de credieten wordt bedoeld.

Onmiddellijk daarop volgt n.l.: ,,de voorschotten aan het bedrijfsleven plegen voor en na verstrekt te worden in de vorm van opvraagbare rekeningcourant-credieten". Dit laatste zegt niets omtrent de doeleinden, waarvoor de credieten worden verstrekt en in verband daarmee omtrent de termijn gedurende welke de debetsaldi gemiddeld blijven uitstaan. De rekeningcourantvorm kan gebleven zijn, doch dit betekent niet dat het doel waarvoor de credieten werden verleend en de gemiddelde duur der credieten onveranderd is gebleven. Indien de gemiddelde duur, waarop debetsaldi uitstaan in verband met de financiering van totnogtoe ongebruikelijke objec-

18) Voor 1950 werd genomen de gecombineerde balans van 42 handelsbanken. Deze is niet helemaal vergelijkbaar met de hedentendage gepubliceerde geconsolideerde balans der representatieve banken. Deze afwijking is echter niet belangrijk.

$\mathrm{m} \mathrm{a} \mathrm{b}$ blz. 121 
ten, verlengd blijkt te zijn, zouden wij zeggen, dat de aard wél veranderd is. In het reeds eerder geciteerde artikel .,Tien jaren bankpolitiek" merkt Verrijn Stuart op, dat op een bepaald terrein wel degelijk een wijziging in de politiek der algemene banken heeft plaats gehad. Hij bedoelt daarmee ,.de grote uitbreiding van het afbetalingscrediet, dat in stijgende mate over de algemene banken loopt" en hij licht dit als volgt nader toe: „Drie grote banken hebben zich rechtstreeks geïnteresseerd bij instellingen voor afbe. talingscrediet. Twee van deze banken hebben elk voor de helft een grote instelling voor afbetalingscrediet overgenomen ...... De derde der hier bedoelde grote banken heeft een andere instelling voor afbetalingscrediet overgenomen ...... Een der zoëven bedoelde banken heeft een dochterinstelling opgericht, die zich op dit gebied beweegt en die naar verluidt een snelle ontwikkeling vertoont" 19). Wij zouden deze woorden van Verrijn Stuart als volgt willen vertalen: De Amsterdamsche Bank en R. Mees en Zonen hebben op fifty-fifty basis de Hollandsche Disconterings Maatschappij overgenomen. De Twentsche Bank heeft de Industriële Disconto Maatschappij overgenomen en de Amsterdamsche Bank heeft de N.V. Mij. tot financiering van Huurkoopovereenkomsten opgericht. De betreffende deelnamen zijn uiteraard onder „Deelnemingen" geboekt en waarschijnlijk ook de aan de betr. maatschappijen verstrekte credieten. Het is echter geenszins uitgesloten dat ook onder debiteuren credieten aan deze en andere soortgelijke maatschappijen zijn geboekt.

Wanneer door middel van de uitgifte van obligaties middelen worden aangetrokken voor de financiering van afbetalings- en huurkoopcontracten lijkt ons dit wel te motiveren. De termijnen voor deze credieten zijn weliswaar meestal niet zeer lang, doch ook weer niet zo, dat van korte credieten kan worden gesproken. Bovendien zullen ze bij de financierende bank een permanent beslag op middelen leggen en - naar heden ten dage mag worden aangenomen - in toenemende mate. De rentewinst op deze financieringen is meestal aanzienlijk, zodat de relatief hoge prijs, welke voor het obligatiekapitaal betaald moet worden geen enkel bezwaar vormt. De afwenteling van deze credieten op de kapitaalmarkt ligt ook in de lijn van de opvattingen van De Nederlandsche Bank, blijkens een begin september j.1. door de Nederlandsche Bankiersvereniging uitgegeven communiqué. Twee sectoren uit de credietverlening der banken werden door de President van De Nederlandsche Bank aangediend als bijzonder geschikt aangrijpingspunt voor een temporisering van de uitbreiding der credietverlening:

1. de financiering van het afbetalingscrediet en

2. het investeringscrediet, waaronder mede te verstaan credieten ter fi nanciering van permanente behoeften aan bedrijfskapitaal 20 ).

Ongeveer een maand later verscheen het prospectus van de Amsterdamsche Bank over de uitgifte der deposito-obligaties. Verband met verleende afbetalings- en investeringscredieten lijkt ons geenszins uitgesloten en uit dezen hoofde zou het voor de banken nieuwe financieringsinstrument ook elders kunnen worden toegepast. Te bezien valt hoe de duur der leningen kan worden ,getimed" dan wel doorlopende afgifte ,over the counter", aangepast aan de behoefte voorkeur verdient. Daarbij ware dan te wensen, dat in de jaarstukken van de banken duidelijk het verband tussen afbetalingsfinanciering en de daarvoor aangewende middelen tot uitdrukking werd gebracht, opdat ook buitenstaanders zich daaromtrent een oordeel kunnen vormen!

19) Jubileumbundel Herstelbank blz. 67/68.

20) Zie Fin. Dagblad, dd. 13-9-55.

$\mathrm{m}$ a b blz. 122 